\title{
Itinerários da Esperança: uma hermenêutica da realidade pandêmica à luz da trilogia cinematográfica $O$ Senhor dos Anéis
}

\author{
Itineraries of Hope: \\ a hermeneutic of the pandemic reality in the light movies \\ trilogy The Lord of the Rings
}

Letícia Alves Duarte de Souza*

\section{Resumo}

No ano de dois mil e vinte, o mundo se viu de portas fechadas devido à pandemia que se instalara. Enquanto milhares de pessoas não conseguiam respirar, o planeta respirava diante destas portas que se encontravam fechadas. A crise social tornou-se ainda mais evidente e junto a tudo isto, o medo e a desesperança que nos afligiam ao vermos e sentirmos a morte de tantas pessoas. Porém, a esperança é um sentimento intrínseco do ser humano. Se existimos, então possuímos esperança mesmo que esta esteja perto do fim. No cristianismo, a esperança está ligada diretamente a morte e ressurreição de Jesus Cristo. Sendo assim, fazendo uso da literatura fantástica de J. R. R. Tolkien, especificamente em $O$ Senhor dos Anéis, com base nos filmes, este artigo propõe-se a apresentar a esperança nesta obra, traçando um paralelo a realidade pandêmica em que nos encontramos, além dos elementos teológicos que se fazem presente no estudo da escatologia da esperança.

Palavras-chave: Esperança. Tolkien. Literatura. Escatologia.

* Artigo submetido em 31/03/21 quando a autora ainda era mestranda na PUC-Rio. 


\begin{abstract}
In the year of two thousand and twenty, the world found itself behind closed doors due to the pandemic that had set in. While thousands of people were unable to breathe, the planet was breathing in front of these closed doors. The social crisis became even more evident and along with all this, the fear and hopelessness that afflicted us when we saw and felt the death of so many people. However, hope is an intrinsic feeling of the human being. If we exist, then we have hope even if it is nearing its end. In Christianity, hope is directly linked to the death and resurrection of Jesus Christ. Thus, making use of the fantastic literature of J. R. R. Tolkien, specifically in The Lord of the Rings, based on the films, this article proposes to present hope in this work, drawing a parallel to the pandemic reality in which we find ourselves, in addition to the theological elements that are present in the study of the eschatology of hope.
\end{abstract}

Keywords: Hope. Tolkien. Literature. Eschatology.

\title{
Introdução
}

Certas vezes, quando lemos livros que possuem histórias ficcionais, somos transportados até aquele mundo através da leitura, mas sabemos não ser real aquilo que lemos. Porém, a literatura possui a capacidade de transcender os reais significados pelos quais estamos habituados a viver.

Se para a literatura o ser humano importa, para a Teologia não é diferente. Sendo assim, a esperança que nos perpassa enquanto seres humanos está presente em diversas páginas, inclusive, na Bíblia que lemos. Não apenas a literatura, mas a arte possui este poder de captação do ser humano, produzindo experiências. Segundo Adélia Prado, a arte não tem natureza racional, mas sim no espírito. De fato, em meio à pandemia de dois mil e vinte um, a arte se mostrou necessária para que sobrevivêssemos ao caos, ao medo e à dor que se instalava no mundo. O cinema é considerado a sétima arte e tem grande influência nas nossas vidas, tendo uma maior amplitude com os serviços de streaming. Desta maneira, o propósito deste artigo é apresentar uma hermenêutica acerca da esperança em $O$ Senhor dos Anéis de J. R. R. Tolkien em relação à realidade pandêmica em que o mundo se encontrou no ano de dois mil e vinte.

Faz-se necessário explicar que a escolha dos filmes para a abordagem do tema se deu porque foi assistindo aos filmes que toda a inspiração para a escrita 
ocorreu. Durante o início da pandemia, permeados pelo cansaço, medo e dúvida, ao estudar sobre a escatologia da esperança, a ótica da esperança no filme se fez presente. Contudo, o livro é citado porque é a obra principal e primeira de $O$ Senhor dos Anéis, e posteriormente, buscaremos um aprofundamento no assunto mediante a literatura de J. R. R. Tolkien, para uma abordagem maior acerca do tema.

Sendo assim, a primeira parte trata do autor e o contexto em que a obra foi escrita, e em seguida, há um breve resumo da estória. A segunda parte se dedica ao estudo da esperança e como esta se dá no cristianismo. E por fim, a terceira parte trata especificamente do que se é proposto neste trabalho. Seguindo então a conclusão e referências.

\section{Uma breve apresentação da Trilogia "O Senhor dos Anéis"}

A trilogia $O$ Senhor dos Anéis foi escrita por J. R. R. Tolkien entre os anos de 1936 e 1949, sendo uma história dividida em seis livros publicados em três volumes, em 1954 e 1955, a saber, A Sociedade do Anel, As Duas Torres e O Retorno do Rei, respectivamente.

Colecionando uma legião de fãs ao longo dos anos, esta obra foi traduzida em diversos idiomas. Os livros foram também adaptados para o rádio, para o teatro e para uma animação. A adaptação para o cinema, objeto do presente artigo, teve, respectivamente, lançamento em 2001, 2002 e 2003. A trilogia cinematográfica foi ganhadora de diversos prêmios, incluindo o Oscar de melhor filme para O Senhor dos Anéis: O Retorno do Rei, de 2003. Recentemente a trilogia cinematográfica foi disponibilizada, também, em diversas plataformas de streaming.

\subsection{Sobre J. R. R. Tolkien e seu contexto}

J. R. R. Tolkien nasceu na África do Sul em 1892, mas mudou-se ainda novo para a Inglaterra. Tolkien viveu no contexto de transição do século XIX para o século XX, lidando com os enfrentamentos da Modernidade e sendo um crítico em relação a mesma. Segundo Diego Genú Klautau, O Senhor dos Anéis "se expressa como obra literária de caráter religioso católico, que está contextualmente fortemente inserido nos fundamentos da modernidade, e assim realiza uma crítica a essa mesma modernidade". ${ }^{1}$ Foi professor em Oxford, onde se aposentou, porém enfrentou a Primeira Guerra Mundial

\footnotetext{
${ }^{1}$ KLAUTAU, D. G., O Bem e o Mal na Terra Média, p. 13.
} 
simultaneamente com a sua formação acadêmica. É importante ressaltar que Tolkien escreveu $O$ Senhor dos Anéis dentro do contexto da Segunda Guerra Mundial.

\subsection{A estória}

Antes de falar propriamente da estória, para uma melhor compreensão, é importante saber acerca do universo tolkiano no qual ela se passa. Tolkien possui o seu próprio universo que se passa na Terra Média, e além de o conhecermos em $O$ Senhor dos Anéis, também o temos em $O$ Hobbit (que seria a narrativa anterior ao nosso objeto de estudo), $O$ Silmarillion, dentre outros. Esta terra era habitada por diversas criaturas, como Elfos, Magos, Ents, Hobbits, Anões, Homens, Orcs, Trolls e Dragões.

A narrativa de $O$ Senhor dos Anéis é iniciada três mil anos antes dos acontecimentos descritos na narrativa principal do livro. Sauron, o Senhor do Escuro, forjou secretamente o Um Anel que lhe conferia o poder de governar a todos e aprisioná-los na escuridão. Mediante ao Um Anel, todas aqueles que estivessem usando os anéis do poder que foram forjados pelo Elfo Celebrimor, deixavam de ter força e autoridade, e passavam a obediência e dependência. Conforme lemos:

Três Anéis para os élficos reis sob o céu,

Sete para os Anões em recinto rochoso,

Nove para os Homens, que a morte escolheu,

Um para o Senhor Sombrio no espaldar tenebroso

$\mathrm{Na}$ terra de Mordor aonde a Sombra desceu.

Um Anel que a todos rege, Um Anel para achá-los, Um Anel que a todos traz paz para na escuridão atá-los.

$\mathrm{Na}$ terra de Mordor aonde a Sombra desceu. ${ }^{2}$

Quando Sauron trouxe a escuridão para toda a Terra Média, homens, elfos e anões uniram-se para derrotá-lo, e Isildur, rei de Gondor, cortou a mão em que Sauron carregava o Um Anel, o que levou a sua derrota. Porém, o Um Anel precisava ser destruído na Montanha da Perdição onde fora forjado, mas ao ser capturado por seu poder, Isildur não o destruiu sendo consumido pelo poder que emanava do anel. Então, o anel se perdeu por anos e anos até ser encontrado por Gollum, que o tomou e o guardou, tornando-se submisso ao "precioso".

${ }^{2}$ TOLKIEN, J. R. R., A Sociedade do Anel, p. 103. 
Escondido nas cavernas com Gollum, o anel se vai ao ser encontrado por um hobbit do Condado, Bilbo Bolseiro (lemos acerca deste acontecimento em $O$ Hobbit). Bilbo demonstra uma boa resistência ao poder do anel, mas não o suficiente para se desfazer dele, guardando-o consigo por mais alguns anos.

Gandalf, o cinzento, era um mago que levou Bilbo para sua jornada de aventura e tornaram-se bons amigos. Em seu aniversário de cento e onze anos, Bilbo decide que é hora de partir para mais uma jornada e desaparece em sua própria festa. De que maneira? Ao colocar o Um Anel ele ficara invisível e pôde ir sem que ninguém o impedisse. Porém, Gandalf sabia que anéis mágicos não eram capazes de tal coisa. É quando percebe como Bilbo tinha dificuldade de deixar o anel, então, convence-o a deixá-lo e o entrega a Frodo, sobrinho de Bilbo, ao ir em busca de respostas.

É neste ponto que a saga para destruição do anel é começada. Sauron precisava do Um Anel para conseguir tomar sua forma novamente, e para isso, envia os espectros do anel para encontrá-lo. O mago Saruman que deveria estar aliado aos povos da Terra Média, passou para o lado de Sauron e guiou os orcs em sua preparação para uma nova guerra, estes tinham sua fortaleza em Mordor, onde ficava o Grande Olho (de Sauron) e a Montanha da Perdição, onde o anel precisava ser destruído.

Frodo segue nessa caminhada com seu amigo e fiel escudeiro Samwise Gamge, e acabam por encontrar dois amigos no início da jornada e que seguem com eles até o fim, Peregrin Tûk, o Pippin, e Meriadoc Brandebuque, o Merry. Estes devem chegar em Valfenda para deixar o Um Anel com os elfos, porém, Elrond explica para Gandalf que os elfos não conseguiriam impedir o exército de Sauron. Sendo assim, convocou-se homens e anões para que se juntassem aos elfos e a Gandalf em uma reunião que seria decidido quem levaria o anel até Mordor. Frodo voluntariou-se e junto a ele foram seus três amigos hobbits, Gandalf, Légolas (o Elfo), Gimli (o Anão), Boromir (um homem, príncipe de Gondor) e Aragorn (um homem, descendente de Isildur, herdeiro legítimo do trono de Gondor). Foi formada assim, a Sociedade do Anel, que ajudou Frodo em sua missão e conseguiu derrotar Sauron e seu exército.

\section{A esperança}

Segundo o dicionário Michaelis, esperança é: "Ato de esperar aquilo que se deseja obter; expectativa na aquisição de um bem que se deseja; aquilo que se espera, desejando; a segunda das três virtudes teologais". 3 A esperança

\footnotetext{
${ }^{3}$ MICHAELIS, Esperança. As três virtudes teologais são a fé, a esperança e a caridade.
} 
encontra-se no ser humano e é intrínseca ao nosso ser. Todos nós esperamos algo para além do que se espera, ainda que não se acredite em um por vir.

\subsection{A esperança cristã}

Tanto o cristianismo quanto o judaísmo estão atrelados à esperança. Noé entrou na arca com a esperança de que sairia dela; Abraão tinha esperança que a promessa dada por Deus a ele se cumpriria; Moisés tinha esperança de que o povo hebreu seria liberto e chegariam na Terra Prometida; Josué tinha esperança de que a conquistariam; Davi tinha esperança de que seria rei; dentre tantos outros personagens que lemos e ouvimos nas narrativas bíblicas. O povo judeu possui a esperança da vinda do Messias, já os cristãos, possuem a esperança da sua segunda vinda.

Quando nos debruçamos no Antigo e no Novo Testamento, percebemos a relação que existe entre a esperança e a promessa. Deus é um deus que promete ao seu povo, e este povo, por sua vez, espera com esperança, como citado em algumas ocorrências no parágrafo acima.

A esperança cristã é dada na fé, e esta é "a certeza daquilo que esperamos e a prova das coisas que não vemos" (Hb 1,1). Esta esperança nos é dada em Jesus, pois é nele que a promessa de salvação é estabelecida, e através de sua morte e ressurreição a esperança cristã concentra-se na parusia, no Reino de Deus, na ressurreição do homem, na vida eterna. Neste esperar encontra-se a tensão escatológica da igreja naquilo que já nos foi dado e aquilo que ainda há de vir.

Segundo Cesar Kuzma:

Falar de esperança é falar da força positiva que nos faz caminhar rumo a um horizonte, onde apenas a alegria de estar caminhando já é de certa forma, transformadora da realidade. É uma força que transcende toda e qualquer experiência humana; é uma expectativa que aspira algo supremo, intocável, infinito. Por esta razão, torna-se difícil descrevê-la, antes é preciso se deixar envolver por ela, pois apenas a esperança nos faz desfrutar, já no presente, um kairós vivificante e anunciador de um ainda não futuro. Por isso, as promessas (passado), se transformam em prelúdios futuros, nos quais já é vislumbrado, mesmo que precocemente, um ainda não (futuro), mas que preconiza, por assim dizer, um eterno presente. $^{4}$

\footnotetext{
${ }^{4}$ KUZMA, C. A., A esperança cristã, p. 20.
} 


\subsection{A esperança escatológica}

Apesar de ter a morte como uma de suas questões centrais, os cristãos ainda possuem um certo revés a ela. Para onde, pois, iremos após a morte? O imaginário cristão foi recheado de respostas míticas ao buscar saber de questões como o juízo, purgatório, o que seria da alma e do corpo, por exemplo. Porém, segundo Luis Carlos Susin, este tipo de narrativa mítica não é mais adequado para nos estabelecer respostas. ${ }^{5}$

Ao longo da história, diversas teorias, correntes e interpretações escatológicas foram desenvolvidas. $\mathrm{O}$ fim interessa ao cristão, pois é nele que se estabelece a plenitude do Reino de Deus, Moltmann comenta: "Reino de Deus significa originariamente reino em promessa, fidelidade e cumprimentos. A vida neste reino significa, portanto, peregrinação histórica, movimento e obediente prontidão frente ao futuro". ${ }^{6}$

Jürgen Moltmann inicia seu livro "A vinda de Deus: escatologia cristã" com uma espécie de panorama acerca da escatologia. O século XIX foi o século da "era cristã", devido a todo o contexto de colonização por parte dos povos europeus, o que difundiu o "fervor missionário messiânico". ${ }^{7}$ Contudo, no século XX, o que se encontra são duas guerras mundiais e milhares e milhares de mortes. Segundo Moltmann:

O Mundo Cristão juntamente com a sua Era Cristã naufragou de uma forma terrível: em duas guerras mundiais ele destruiu a si mesmo. Os povos libertaram-se dos impérios coloniais. Em "Auschwitz" foi apagado o sonho judaico-cristão da assimilação dos judeus ao mundo cristão. Em "Hiroshima" a humanidade perdeu a sua inocência atômica, em "Chernobil", sua inocência ecológica. Os horrores da história do século $\mathrm{XX}$ arruinaram de modo irremediável todos os projetos quiliásticos e messiânicos do século XIX, tanto em sua forma religiosa quanto secular. O que tomou o seu lugar? Em muitos povos e em muitos âmbitos da vida eles foram substituídos pelo apocalipsismo, seja na forma religiosa, seja na forma secular [...] o apocalipsismo moderno busca o escatológico negativamente para dentro da história, para praticar, já aqui na terra, o "Armagedom" nuclear e o "Chernobil" ecológico. ${ }^{8}$

\footnotetext{
${ }^{5}$ SUSIN, L. C., O tempo e a eternidade, p. 16.

${ }^{6}$ MOLTMANN, J., Teologia da Esperança, p. 273.

${ }^{7}$ MOLTMANN, J., A vinda de Deus, p. 19.

${ }^{8}$ MOLTMANN, J., A vinda de Deus, p. 21.
} 
Desta forma, neste período foram desenvolvidas diversas correntes escatológicas com base no apocalipsismo. Recentemente, isto veio à tona mais uma vez devido ao contexto da pandemia e a morte tornou-se quase que comum, pois os números não pararam de subir por meses e meses. Diante do mal que se instalara, dois posicionamentos puderam ser observados: aqueles que de alguma forma buscaram ajudar nesta situação; e aqueles que em nome de Deus, declararam a sua ira sendo estabelecida. Adentraremos mais neste assunto no próximo tópico.

Contudo, a escatologia é mais que uma doutrina cristã, ou uma das áreas de estudo teológico, ou ainda o "estudo das últimas coisas", mas sim, se encontra no cerne do cristianismo, e segundo, Moltmann, orienta toda pregação e mensagem cristã. ${ }^{9}$ Segundo este:

O cristianismo é total e visceralmente escatologia, e não só como apêndice; ele é perspectiva, e tendência para frente, e, por isso mesmo, renovação, e transformação do presente. O escatológico não é algo que se adiciona ao cristianismo, mas é simplesmente o meio em que se move a fé cristã. [...] De fato, a fé cristã vive da ressurreição do Cristo crucificado e se estende em direção às promessas do retorno universal e glorioso de Cristo. ${ }^{10}$

\section{A esperança em $O$ Senhor dos Anéis}

\subsection{Terra de esperança}

"O fogo de Isengard se espalhará e as florestas de Tuqueburgo e da Terra dos Buques serão incendiados, e tudo o que foi verde e bom neste mundo terá desaparecido". ${ }^{11}$

A frase acima é proferida por Merry quando um ent, Bárbarvore, comunica a ele que os ents decidiram que não lutariam a guerra contra Sauron e os homens, e que levariam tanto Merry, quanto Pippin até certo ponto da floresta para que estes retornassem ao Condado. Merry ficou inconformado, enquanto Pippin acreditava que talvez a guerra fosse maior do que eles, e eles tinham o Condado.

\footnotetext{
${ }^{9}$ MOLTMANN, J., Teologia da Esperança, p. 30.

${ }^{10}$ MOLTMANN, J., Teologia da Esperança, p. 30.

${ }^{11}$ O SENHOR DOS ANÉIS: as duas torres. Direção: Peter Jackson. Estados Unidos: New Line Cinema, 2002. Serviço de Streaming, 142 min.
} 
Visto a relação de domínio que nós homens desta Terra exercemos sobre tudo o que é verde, puro e natural, não é exagerado comparar a fala e raciocínio de Merry aos nossos dias. Isto pode ser analisado no cenário de pandemia que o mundo se deparou no início de 2020, pois quando a reclusão do ser humano foi necessária para a prevenção e controle do vírus, o planeta voltou a respirar.

No capítulo 14 do livro "Unidade na Pluralidade", García Rubio nos apresenta o fato do avanço tecnológico levar o ser humano a crer que tem domínio sobre a natureza, um domínio destruidor. Ele discorre sobre a ideia do ser humano estar doente e esta doença do homem levar ao adoecimento da Terra. Ele diz que "todo organismo que destrói o seu meio ambiente se autodestrói". ${ }^{12}$ Já o Papa Francisco apresenta o paradigma tecnocrático em sua encíclica Laudato si', pois o avanço tecnológico não corresponde a restauração dos recursos naturais.

No Gênesis, o ser humano é antes de tudo um ser criado, assim como toda a natureza. A ideia apocalíptica de fim do mundo, os conceitos dualistas e o desejo pelo céu, muitas vezes nos levam a esquecer a casa comum em que vivemos, nos levam a esquecer que fomos feitos mordomos e não donos desta terra.

\subsection{A esperança ao outro}

Em determinado ponto da história de $O$ Senhor dos Anéis, o exército que saiu em defesa da Terra Média contra Sauron se vê desesperançado por estarem em um número menor, porém, permaneceram todos dispostos a darem suas vidas na batalha. Antes de iniciá-la, ocorre o seguinte diálogo entre Gimli (o anão) e Légolas (o elfo) que historicamente são inimigos:

- Nunca pensei que morreria lutando lado a lado de um elfo.

- E lado a lado com um amigo?

- Sim. Eu poderia fazer isso. ${ }^{13}$

Trazendo ao nosso contexto, o Papa Francisco na Laudato Si' afirma que não possuímos duas crises, uma ecológica e uma social, mas sim uma única crise socioambiental, e "as directrizes para a solução requerem uma abordagem integral para combater a pobreza, devolver a dignidade aos excluídos e, simultaneamente, cuidar da natureza". ${ }^{14}$ No atual cenário de pandemia, as

${ }^{12}$ GACIA RUBIO, A., Unidade na Pluralidade, p. 445.

${ }^{13}$ O SENHOR DOS ANÉIS: o retorno do rei. Direção: Peter Jackson. Estados Unidos: New Line Cinema, 2003. Serviço de Streaming, 154 min.

${ }^{14}$ LS 139. 
diferenças sociais do globo terrestre tornaram-se ainda mais evidentes. Se a melhor forma de prevenção ao coronavírus é a higienização, em diversos lugares sequer tem água para que se lavem as mãos.

No Brasil, especificamente, vivemos dois horrores, a pandemia e o nosso cenário político-social. Sendo assim, ao se falar de fazer, manter e estender uma quarentena, muitos olhares decidiram voltar-se aos pobres, pois estes precisam trabalhar para ter o sustento e não possuem uma estrutura adequada para permanecer em quarentena. Contudo, este discurso se deu apenas para camuflar as reais intenções de se manter uma economia em troca da vida daqueles que "valem menos". No entanto, não apenas em uma pandemia, mas em nossa existência, nossas esperanças de vida deveriam estar atreladas. A igreja deveria ser esse caminho de esperança ao outro, e isto de fato se deu quando a igreja voltou-se para a opção preferencial pelos pobres na América Latina. Gustavo Gutiérrez diz que "a comunidade cristã torna-se, assim, um sinal do Reino de Deus na história deste continente". ${ }^{15}$

Quando nos deparamos com o cenário de pobreza, opressão e descaso ao outro, as palavras de Mateus ficam ainda mais evidenciadas e atual e provocador é o diálogo: "Senhor, quando que é que te vimos com fome ou com sede, forasteiro ou nu, doente ou preso e não te socorremos?' [...] 'Em verdade vos digo: todas as vezes que o deixastes de fazer a um desses mais pequeninos..."” (Mt 25,44-45).

\subsection{O retorno do rei}

Após a derrota de Sauron e seu exército, Aragorn, herdeiro legítimo de Isildur, é coroado como o rei de Gondor. Antes, ele era um Guardião do Norte e passou parte da sua vida em Valfenda com os elfos. Aragorn mantia sua verdadeira identidade escondida, mas quando a ameaça de Sauron ressurgiu, ele se tornou parte da Sociedade do Anel e assumiu sua identidade, e ao ser coroado, o povo de Gondor teve o "Retorno do Rei".

Como já foi discorrido anteriormente, o cristianismo desde seu início possui uma esperança: o retorno do Rei, ou seja, a segunda vinda de Jesus. A constituição da eclesiologia do primeiro século é baseada nessa esperança messiânica. Ainda hoje, esta esperança existe na igreja, contudo ela se concentra em uma expectativa apocalíptica. Através de leituras e estudos dos textos que apontam para o fim do mundo, essa construção se dá em cima da narrativa do medo e do juízo.

${ }^{15}$ GUTIÉRREZ, G., Onde dormirão os pobres?, p. 5. 
Estes dias trouxeram de maneira mais intensa o olhar desta esperança apocalíptica e de juízo sobre muitos. Enquanto caminhões com corpos passavam pela Itália, julgamentos eram estabelecidos à moda pedagógica vista no Antigo Testamento. O Deus encarnado que lemos, que abriu mão de sua glória, foi humilhado e traído, morto, mas que ressuscitou, nos apresenta um evangelho de amor e cuidado, de olhar o outro e amar, e sim, ele também apresenta a justiça, mas esta não se faz por interesses, um exemplo é o relato acerca da mulher adúltera. Em Jo 8,1-11, lemos acerca deste relato, cuja lei, citada pelos escribas e fariseus, dizia que aquela mulher, levada até a presença de Jesus, deveria ser apedrejada. O que esperavam é que ele dissesse que sim e que procedessem com tal ato, afinal, a Lei de Moisés instruía isso, porém, as palavras de Jesus foram outras: "Aquele que dentre vós está sem pecado seja o primeiro que atire pedra contra ela" (v. 7). Nenhum daqueles que a acusavam ficaram, e olhando para aquela mulher Jesus disse que também não a condenava, apenas a instruiu dizendo: "vai-te e não peques mais" (v.11). A Lei que para aqueles escribas e fariseus era de suma importância, foi posta de lado, e a vida daquela mulher valia mais do que a doutrina, porque esta é a justiça que Jesus nos apresenta, uma justiça que olha e se importa com o outro.

Em "O Senhor dos Anéis", Aragorn sabia que tinha direito ao trono, mas nunca recorreu de fato a ele, antes decidiu lutar para que a Terra Média e os seus povos sobrevivessem. Nós, enquanto cristãos, temos a esperança de que Jesus voltará e com ele será estabelecido o seu reino. A pergunta não é como isso acontecerá ou como seremos ou não salvos, mas sim, como nós temos nos portado diante desta esperança que nos foi dada. Que tipo de resposta a igreja pode dar hoje?

O problema do mau permanece presente e parte dos cristãos ainda se mantém somente na atitude que Peter Berger nos apresenta: "o complexo messiânico-milenarista postula uma teodicéia porque relativiza o sofrimento ou a injustiça do presente em termos de serem vencidos num futuro glorioso". ${ }^{16} \mathrm{O}$ filósofo e romancista Albert Camus nos recorda: "Há vinte séculos, a soma total do mal não diminuiu no mundo. Nenhuma parusia, quer divina ou revolucionária, se realizou. Uma injustiça continua imbricada em todo sofrimento, mesmo o mais merecido aos olhos dos homens". ${ }^{17}$

Não que a fé na parusia e a esperança de um futuro glorioso deva ser deixada de lado, mas a esperança é o que irá nos ajudar a sobreviver a estes dias. Se analisarmos a forma como essa pandemia se deu e como o meio

\footnotetext{
${ }^{16}$ BERGER, P. L., O dossel sagrado, p. 81.

${ }^{17}$ CAMUS, A., O homem revoltado, p. 370.
} 
ambiente tem respondido a este isolamento do ser humano, é possível enxergar de uma melhor forma um convite a integralidade de fato do ser e do seu existir no meio que vive, além da fragilidade do humano e da necessidade de enxergarmos uns aos outros.

\section{Conclusão}

Mediante o cenário de pandemia que o mundo se encontrou em 2020, o modo de viver do ser humano precisou ser revisto e modificado, ainda que a pequenos passos para alguns, ou radicalmente para outros. Neste ambiente, viuse como a arte é essencial para a vida, seja a escrita, a pintura, a música, o audiovisual, e neste sentido, a literatura fantástica de J. R. R. Tolkien nos leva a uma profunda reflexão e associação aos nossos dias.

A esperança é presente em cada ser humano, sendo individual, Piazza ${ }^{18}$ nos leva a um entendimento acerca da esperança responsável, já que ela está também ligada às decisões que tomamos em nossa existência. Contudo, cada um de nós vive nesta "Terra Média" que nos foi dada pelo Criador, não para domínio, pois nós vivemos em uma inter-relação com esta casa comum, e por isso, é no coletivo que esta esperança também se manifesta.

Por fim, as palavras de Cesar Kuzma são necessárias ao dizer que:

Se a esperança é a esperança da fé e a fé é vivida neste mundo, aonde Cristo veio e inaugurou o seu Reino, então é neste mundo, com todas as suas variações e situações, que devemos atuar como sal da terra e luz do mundo, sendo sinal e prova dessa esperança. É neste mundo que somos convidados, enquanto Igreja, comunidade de fé e povo de Deus, a viver e alimentar essa esperança coletivamente, pois aquilo que esperamos se espera para todos, e com todos. ${ }^{19}$

Sendo assim, nossa esperança está naquilo que é e ainda não é, pois, o Reino de Deus se manifesta mesmo que ainda não em sua plenitude. Como cristãos, precisamos seguir a missão da esperança como Frodo e a Sociedade do Anel seguiram até Mordor e unidos, mesmo em suas diferenças, lutaram e venceram pela Terra Média.

\footnotetext{
18 PIAZZA, O. F., A esperança.

${ }^{19}$ KUZMA, C., O futuro de Deus na missão da esperança, p. 58.
} 


\section{Referências bibliográficas e cinematográficas}

BÍBLIA de estudo. Almeida revista e corrigida. 4.ed. Rio de Janeiro: CPAD, 2015. BÍBLIA de Jerusalém. Nova ed. rev. e ampl. 2. impr. São Paulo: Paulus, 2003. BERGER, P. L. O dossel sagrado: elementos para uma teologia sociológica da religião. São Paulo: Paulus, 1985.

CAMUS, A. O homem revoltado. Rio de Janeiro: BestBolso, 2017.

FRANCISCO, PP. Carta Encíclica Laudato si’: sobre o cuidado da casa comum. Brasília: CNBB, 2015. Disponível em: $<$ http://www.vatican.va/content/francesco/pt/encyclicals/documents/papafrancesco_20150524_enciclica-laudato-si.html>. Acesso em: 17 jun. 2020.

GARCIA RUBIO, A. Unidade na Pluralidade: o ser humano à luz da fé e da reflexão cristãs. São Paulo: Paulus, 1989.

GUTIÉRREZ, G. Onde dormirão os pobres? São Paulo: Paulus, 2003.

KlautaU, D. G. O Bem e o Mal na Terra Média: a filosofia de Santo Agostinho em $O$ Senhor dos Anéis de J. R. R. Tolkien como crítica à modernidade. São Paulo, 2007. 255p. Dissertação. Faculdade de Ciências da Religião, Pontifícia Universidade Católica de São Paulo.

KUZMA, C. A. A esperança Cristã: fundamentos e reflexões na teologia de Jürgen Moltmann. Rio de Janeiro, 2007. 165p. Dissertação. Faculdade de Teologia, Pontifícia Universidade Católica do Rio de Janeiro.

KUZMA, C. A. O futuro de Deus na missão da esperança: uma aproximação escatológica. São Paulo: Paulinas, 2014.

MICHAELIS. Esperança. Disponível em: $<$ https://michaelis.uol.com.br/moderno-portugues/busca/portuguesbrasileiro/esperan\%C3\%A7a/>. Acesso em: 17 jun. 2020.

MOLTMANN, J. A vinda de Deus: escatologia cristã. São Leopoldo/RS: UNISINOS, 2003.

MOLTMANN, J. Teologia da Esperança: Estudos sobre os fundamentos e as consequências de uma escatologia cristã. São Paulo: Teológica / Loyola, 2005. PIAZZA, O. F. A esperança: lógica do impossível. São Paulo: Paulinas, 2004. 
SUSIN, L. C. O tempo e a eternidade: a escatologia da criação. Petrópolis/RJ: Vozes, 2018.

TOLKIEN, J. R. R. A Sociedade do Anel: Primeira parte de O Senhor dos Anéis. Rio de Janeiro: Harper Collins Brasil, 2019.

O SENHOR DOS ANÉIS: a sociedade do anel. Direção: Peter Jackson. Estados Unidos: New Line Cinema, 2001. Serviço de Streaming (168 min).

O SENHOR DOS ANÉIS: as duas torres. Direção: Peter Jackson. Estados Unidos: New Line Cinema, 2002. Serviço de Streaming (179 min).

O SENHOR DOS ANÉIS: o retorno do rei. Direção: Peter Jackson. Estados Unidos: New Line Cinema, 2003. Serviço de Streaming (201 min).

\section{Letícia Alves Duarte de Souza}

Mestre em Teologia Sistemático-Pastoral pela Pontifícia Universidade

Católica do Rio de Janeiro

Rio de Janeiro / RJ - Brasil

E-mail: ticialves@ymail.com

Recebido em: 31/03/2021

Aprovado em: 09/06/2021 